\title{
Circulating cartilage oligomeric matrix protein in juvenile idiopathic arthritis
}

Per Lewander, Charlotte Dahle, B. Larsson, J onas Wetterö and Thomas Skogh

The self-archived version of this journal article is available at Linköping University Electronic Press:

http:// urn.kb.se/ resolve?urn=urn:nbn:se:liu:diva-137876

N.B.: When citing this work, cite the original publication.

This is an electronic version of an article published in:

Lewander, P., Dahle, C., Larsson, B., Wetterö, J., Skogh, T., (2017), Circulating cartilage oligomeric matrix protein in juvenile idiopathic arthritis, Scandinavian J ournal of Rheumatology, 46(3), 194-197. https:// dx.doi.org/ 10.1080/ 03009742.2016.1192681

Original publication available at:

https:// dx.doi.org/ 10.1080/03009742.2016.1192681

Copyright: Taylor \& Francis: STM, Behavioural Science and Public Health Titles http:// www.tandf.co.uk/journals/ default.asp 
Title

\section{Circulating cartilage oligomeric matrix protein in juvenile idiopathic arthritis}

Running head

Circulating COMP in JIA

\section{Authors}

Per Lewander, ${ }^{1,2}$ Charlotte Dahle, ${ }^{1,2}$ Brita Larsson, ${ }^{2}$ Jonas Wetterö, ${ }^{1}$ Thomas Skogh, ${ }^{1,2} \#$

1. Division of Neuro and Inflammation Sciences, Department of Clinical and Experimental Medicine, Faculty of Medicine and Health Sciences, Linköping university, SE-58183 Sweden

2. County Council of Östergötland, Sweden

\# corresponding author (thomas.skogh@liu.se)

Key indexing terms:

Cartilage oligomeric matrix protein, Inflammation, Insulin-like growth factor I, Juvenile idiopathic arthritis

Keywords: Cartilage oligomeric matrix protein, C-reactive protein, Juvenile idiopathic arthritis 


\section{ABSTRACT}

Objective. Raised serum cartilage oligomeric matrix protein (sCOMP) has been reported to predict erosive disease in early rheumatoid arthritis. In juvenile idiopathic arthritis (JIA), subnormal sCOMP levels have been associated with on-going inflammation and growth retardation. This study was done to assess sCOMP, C-reactive protein (CRP) and insulin-like growth factor I (IGF-1) in children/adolescents with JIA and in referents.

Methods. 52 JIA patients were enrolled at planned outpatient visits. 54 inpatients with ongoing infection and 120 referents testing negative for IgE-mediated allergy ('IgE-referents') served as controls. All sera were analysed for COMP, IGF-1, and CRP.

Results. Average sCOMP was highest among ‘IgE-referents’ and lowest among ‘infectionreferents'. In JIA sCOMP was not reflected by CRP or clinical signs of disease activity. Conclusion. The results of this study do not support clinical routine sCOMP analysis in patients with JIA. 


\section{Background}

Juvenile idiopathic arthritis (JIA) designates a group of inflammatory joint diseases of unknown aetiology with onset before the age of 16 (1). The disease course is usually self-limiting although a substantial proportion has chronic progressive disease. Considerable efforts have been made to enable prospective structured assessments of disease activity, course and outcome of JIA (2). However, there is still a need to identify early predictors of aggressive disease leading to joint destruction.

'Cartilage oligomeric matrix protein' (COMP) is mainly located in hyaline cartilage, but also in tendons, skin, and synovial fibroblasts (3-5). Growth hormone (GH) and insulin-like growth factor type-1 (IGF-I) up-regulate COMP in cultured human chondrocytes. Serum COMP (sCOMP) increases upon paediatric GH therapy (6). Hepatic IGF-1 production increases as a response to pituitary-gland GH release, which stimulates bone growth and induces COMP gene expression (6).

In early adult rheumatoid arthritis (RA), elevated/rising sCOMP has been reported to predict erosive disease (7). Decreased sCOMP upon treatment with corticosteroids and/or tumour necrosis factor inhibitors has been interpreted as a sign of cartilage protection (8). However, Turesson et al reported raised sCOMP in pre-RA subjects testing negative for anti-citrullinated peptide antibodies, i.e. a risk marker of erosive disease (9).

This study was done to investigate sCOMP, IGF-1 and C-reactive protein (CRP) levels in prevalent JIA 


\section{METHODS}

\section{Subjects}

JIA group: 52 children diagnosed with JIA were recruited, and categorised according to the ILAR classification criteria (1). Enrolment was done at planned visits to a paediatrician (PL) at Vrinnevi hospital, Norrköping, Sweden. Estimation of disease activity was based on presence of $\geq 1$ palpable synovitis and/or motion-induced joint pain. By this definition, $69 \%$ had active disease. 29\% had x-ray proven erosions. Patient characteristics and on-going medications are summarized in Table 1.

Table 1. Characteristics of children with juvenile idiopathic arthritis, on-going infection, and referents testing negative for IgE-associated allergy

\begin{tabular}{|c|c|c|c|c|c|c|c|c|c|}
\hline Mean ag & e (years, 95\% CI) & Sex & Onset type (number) & Disease duration & Disease activity & CRP & IGF-1 & sCOMP & Medication \\
\hline JIA & $12.4(2.0-18.2)$ & $\begin{array}{l}31 \text { girls } \\
21 \text { boys }\end{array}$ & $\begin{array}{l}\text { Oligoarticular (25) } \\
\text { Enthesitis-related (8) } \\
\text { Polyarticular RF+ (4) } \\
\text { Polyarticular RF- (10) } \\
\text { Systemic (0) } \\
\text { Juvenile Pso-related (4) } \\
\text { Undifferentiated (5) }\end{array}$ & $3.9(0.1-15)$ & $\begin{array}{ll}\text { Active: } & n=36 \\
\text { Inactive: } & n=16 \\
\text { Missing: } & n=2\end{array}$ & $\begin{array}{l}\geq 10 \mathrm{mg} / \mathrm{l} \mathrm{n}=11 \\
<10 \mathrm{mg} / \mathrm{l} \mathrm{n}=39\end{array}$ & $\begin{array}{c}330 \mathrm{ng} / \mathrm{l} \\
(291-369)\end{array}$ & $\begin{array}{l}12.2 \mathrm{U} / 1 \\
(3.7-28.7)\end{array}$ & $\begin{array}{ll}\text { Predn } & n=5 \\
\text { MTX } & n=10 \\
\text { SSZ } & n=3 \\
\text { HCQ } & n=1 \\
\text { TNFi } & n=2\end{array}$ \\
\hline $\begin{array}{l}\text { Infectior } \\
\text { ref }\end{array}$ & - $10.6(1.5-18)$ & $\begin{array}{l}33 \text { girls } \\
21 \text { boys }\end{array}$ & & & & $\begin{array}{l}\geq 10 \mathrm{mg} / 1 \quad(\mathrm{n}=54) \\
<10 \mathrm{mg} / \mathrm{l} \quad(\mathrm{n}=0)\end{array}$ & $\begin{array}{c}185 \mathrm{ng} / \mathrm{l} \\
(146-224)\end{array}$ & $\begin{array}{c}6.5 \mathrm{U} / 1 \\
(1.917 .8)\end{array}$ & \\
\hline IgE-ref & $9.2(1.5-17.8)$ & $\begin{array}{l}60 \text { girls } \\
60 \text { boys }\end{array}$ & & & & $\begin{array}{l}\geq 10 \mathrm{mg} / \mathrm{l} \quad(\mathrm{n}=6) \\
<10 \mathrm{mg} / \mathrm{l} \quad(\mathrm{n}=102) \\
\text { missing }(\mathrm{n}=12)\end{array}$ & $\begin{array}{c}245 \mathrm{ng} / \mathrm{l} \\
(213-277)\end{array}$ & $\begin{array}{l}13.7 \mathrm{U} / 1 \\
4.9 .29 .6\end{array}$ & \\
\hline
\end{tabular}

'Infection referents': 54 children hospitalized due to infection, but without signs of arthritis (33 girls; 21 boys, 1.5-18 years, mean 10.6/median 11.7).

'IgE-referents': 120 children testing negative for IgE-antibodies against a panel of common allergens (60 girls/60 boys aged 1.5-17.8 years, mean 9.2/median 9.5).

\section{Serum analyses}

Enzyme-linked immunosorbent assays were used to analyse sCOMP (COMP ${ }^{\circledR}$ ELISA, AnaMar Medical, Göteborg, Sweden) and serum IGF-1 (IGF1-ELISA E20, Mediagnost ${ }^{\circledR}$, Reutlingen, Germany). CRP was analysed turbidimetrically (Advia ${ }^{\circledR}$ 1800, Siemens Healthcare Diagnostics, Terrytown, NY, USA). 


\section{Statistics}

Data are presented as mean values and 95\% confidence interval. For two-group comparisons, unpaired t-test was applied. For three-group comparisons we used UniAnova, and Bonferoni test for multiple comparisons. For correlation analyses the Pearson test was used. The $<5 \%$ level of significance was applied. Statistical analyses were performed using SPSS, version 19 (SPSS, Cary, IL, USA) and GraphPad Prism (GraphPad software Inc, La Jolla, CA, USA).

\section{Ethics considerations}

The study protocol was approved by the regional ethics review board in Linköping (registration number M70-7). Diagnostic COMP kits were provided by AnaMar Medical at a reduced rate without restrictions.

\section{RESULTS}

Average sCOMP was slightly lower in JIA than in IgE-referents $(\mathrm{p}<0.05)$ (Figure 1), but higher compared to infected children $(\mathrm{p}<0.001)$. Overall, sCOMP showed large inter-individual variations. Comparing the younger IgE-referents (0-15 years) with adolescents (16-18 years), average sCOMP was higher among the younger (14.2 U/l \pm 0.45 vs $11.6 \pm 0.7 \mathrm{U} / \mathrm{l} ; \mathrm{p}=0.016$ ). Clinically active/inactive JIA patients did not differ regarding sCOMP levels.

Although not reaching statistical significance, a tendency to higher average CRP was recorded among the 36 clinically active compared to 16 clinically inactive JIA-patients ( $\mathrm{p}=0.053)$. Average CRP was higher among infected children compared both to IgE-referents $(\mathrm{p}<0.0001)$ and JIA $(\mathrm{p}<0.0001)$

Among IgE-referents there was a significant correlation between raised CRP and decreased sCOMP (rho -0.27; $<0.005$ ), but not among infected children (rho -0.12; $=0.4$ ) nor in JIA (Rho 0.023; $=0.87$ ). CRP in JIA and IgE-referents differed significantly. 
Regarding IGF-1, a low negative correlation was registered vis-à-vis CRP (rho = -0.25, p <0.01). IGF-1 levels correlated similarly with age ( $r h o=0.72, \mathrm{p}<0.01)$ in all three populations, whereas no correlations were registered when comparing sCOMP and IGF-1 (rho=0.08, $\mathrm{p}=0.22$ ). IGF-1 was significantly lower among infected children (mean $6.6 \mu \mathrm{g} / \mathrm{l}$ ), compared both to IgE-referents (mean $13.6 \mu \mathrm{g} / \mathrm{l}, \mathrm{p}<0.001$ ) and JIA (mean $12.6 \mu \mathrm{g} / \mathrm{l}, \mathrm{p}<0.001$ ) after correction for age. Compared to IgE-referents, COMP:IGF-1 ratio was significantly lower in JIA as well as in infected children, even when corrected for age.

\section{DISCUSSION}

This study was undertaken to analyse sCOMP levels in JIA patients compared to children/adolescents hospitalised due to on-going infection, and children seronegative regarding IgE-mediated allergy. The few published studies on sCOMP in JIA, have all concluded that sCOMP is reduced during active inflammatory disease $(10,11)$, and that it is related to growth retardation $(6,11)$. Although confirming a tendency to lowered sCOMP in JIA-patients with raised CRP ( $\mathrm{p}=0.053)$, this was not seen comparing patients classified clinically active/inactive.

Discrepancies between different studies may depend on differences in patient materials, reference populations, disease duration, medication, etc.

Our study revealed that cases with infectious disease had markedly lower sCOMP compared to 'IgE-referents’. JIA-patients also had slightly (but statistically significant) lower sCOMP levels than the 'IgE-referents, but distinctly higher levels compared to the infection group. By dividing our JIA cases into a 'low-age group’ (0-15 years) and a higher-aged group (16-18 years) we confirmed lower sCOMP among the older (presumably pubertised) adolescents compared to the lower-aged growing children. 
Like all measurements of circulating biomarkers, interpretation of raised or lowered levels of sCOMP is intricate. Thus, results of serum measurements include aspects on rates of synthesis and degradation, as well as rates of uptake into and clearance from the circulation. Serum concentrations can also be affected by the nature and fate of the circulating analyte, which raises a number of questions, e.g.:

- do reported sCOMP levels reflect native protein and/or degradation fragments?

- can interaction between sCOMP and other circulating proteins (auto-antibodies?) or cells affect the results?

- is the elimination rate of sCOMP and COMP fragments affected by deficient organ function (liver; spleen; kidney)?

- do capture antibodies of the ELISA kit and/or circulating rheumatoid factor interfere with the test results?

Raised levels of sCOMP may thus be explained by increased synthesis e.g. during growth in infancy/adolescence or depending on tissue repair, but could also reflect on-going bone and cartilage destruction during local or systemic inflammation. Different sCOMP fragments may reflect different aspects on synthesis, degradation, elimination rates, etc. Overall, raised sCOMP levels can be induced by growth hormone, which is a likely explanation to elevated sCOMP recorded in children/adolescents during periods of high growth velocity (6). This may well explain the differences regarding positive COMP:CRP correlations reported in adult RA and the opposite in children with systemic inflammation, regardless of underlying cause. Tocilizumab therapy, which is efficiently CRP-lowering, has been shown to raise COMP levels to normal in young persons with JIA (12). Whether or not COMP interacts with CRP is unknown, but both of these molecules bind complement protein C1q, resulting in COMP-mediated inhibition of classical complement activation (13) and CRP-mediated activation of the classical pathway (14). Regarding the effects of GH, it is likely that lowered COMP in JIA relates to growth retardation in patients with on-going inflammation. GH induces IGF-1, which has been reported to be lowered in JIA (15) and, intriguingly, COMP gene expression is up-regulated by IGF-1 (16). Further, it is known 
that sCOMP levels rise in children treated with growth hormone (6). Contrary to the predictive value of sCOMP in early RA with regard to erosive disease (4), Gilliam et al found that sCOMP in JIA patients who did not develop joint erosions and joint space narrowing were higher compared to patients with progressive joint damage (17). In our study, the average sCOMP level was slightly higher in the IgE-negative reference group compared to the JIA-group, which in turn had significantly higher COMP levels compared to children with on-going infection.

The results of this study confirm that clinical and biological correlates of sCOMP differ between children/adolescents and adults, and indicate that sCOMP is of limited clinical value as a biomarker in JIA.

\section{ACKNOWLEDGEMENTS}

We are grateful to the late Dr Jan Hed for initiating this project and for valuable cooperation. We thank laboratory technician Eva Lindbeck for skilled professional assistance, Dr Lars Stenhammar for fruitful discussions, and Dr Karl Wahlin for statistical expertise. 


\section{REFERENCES}

1. Eisenstein EM Berkun Y. Diagnosis and classification of juvenile idiopathic artrhritis. J Autoimmun. 2014;48-49:31-3

2. Abib N. Silman A, Thomson W. Outcome following onset of juvenile idiopathic inflammatory arthritis. I. Frequencies of different outcomes. Rheumatology (Oxford) 2005;44:995-1001

3. Agarwal P, Schulz JN, Blumbach K, Andreasson K, Heinegård D, Paulsson M et al. Enhanced deposition of cartilage oligomeric matrix protein is a common feature in fibrotic skin pathologies. Matrix Biol 2013;32:325-31

4. Lindqvist E, Eberhardt K, Bendtzen K, Heinegård D, Saxne T. Prognostic laboratory markers of joint damage in rheumatoid arthritis. Ann Rheum Dis 2005;64:196-201

5. Muller G, Michel A, Altenburg E. COMP (cartilage oligomeric matrix protein) is synthesized in ligament, tendon, meniscus, and articular cartilage. Connect Tissue Res 1998;39:233-44

6. Bjarnason R, Andersson B, Kim HS, Olsson B, Swolin-Eide D, Wickelgren R et al. Cartilage oligomeric matrix protein increases in serum after the start of growth hormone treatment in prepubertal children. J Clin Endocrinol Metab 2004;89:5156-60

7. Andersson ML, Svensson B, Petersson IF, Hafström I, Albertsson K, Forslind K et al. Early increase in serum-COMP is associated with joint damage progression over the first five years in patients with rheumatoid arthritis. BMC Musculoskelet Disord 2013;14:229

8. Crnkic M, Månsson B, Larsson L, Geborek P, Heinegård D, Saxne T. Serum cartilage oligomeric matrix protein (COMP) decreases in rheumatoid arthritis patients treated with infliximab or etanercept. Arthritis Res Ther 2003;5:R181-5

9. Turesson C, Bergström U, Jacobsson LT, Truedsson L, Berglund G, Saxne T. Increased cartilage turnover and circulating autoantibodies in different subsets before the clinical onset of rheumatoid arthritis. Ann Rheum Dis 2011;70:520-2

10. Urakami T, Manki A, Inoue T, Oda M, Tanaka H, Morishima T. Clinical significance of decreased serum concentration of cartilage oligomeric matrix protein in systemic juvenile idiopathic arthritis. J Rheumatol 2006;33:996-1000

11. Bjørnhart B, Juul A, Nielsen S, Zak M, Svenningsen P, Muller K. Cartilage oligomeric matrix protein in patients with juvenile idiopathic arthritis: relation to growth and disease activity. $\mathrm{J}$ Rheumatol 2009;36:1749-54

12. Nakajima S, Naruto T, Miyamae T, Imagawa T, Mori M, Nishimaki S, Yokota S. Improvement of reduced serum cartilage oligomeric matrix protein levels in systemic juvenile idiopathic arthritis patients treated with the anti-interleukin-6 receptor monoclonal antibody tocilizumab. Mod Rheumatol 2009;19:42-6 
13. Happonen KE, Heinegård D, Saxne T, Blom AM. Interactions of the complement system with molecules of extracellular matrix: relevance for joint diseases. Immunobiology 2012;217:1088-96

14. Sjöwall C, Wetterö J, Bengtsson T, Askendal A, Almroth G, Skogh T, Tengwall P. Solidphase classical complement activation by C-reactive protein (CRP) is inhibited by fluid-phase CRP-C1q interaction. Biochem Biophys Res Commun 2007;352:251-8

15. Allen RC, Jimenez M, Cowell CT. Insulin-like growth factor and growth hormone secretion in juvenile chronic arthritis. Ann Rheum Dis 1991;50:602-6

16. Tian H, Stogiannidis I. Up-regulation of cartilage oligomeric matrix protein gene expression by insulin-like growth factor-I revealed by real-time reverse transcription-polymerase chain reaction. Acta Biochim Biophys Sin (Shanghai) 2006;38:677-82

17. Gilliam BE, Chauhan AK, Low JM, Moore TL. Measurement of biomarkers in juvenile idiopathic arthritis patients and their significant association with disease severity: a comparative study. Clin Exp Rheumatol 2008;26:492-7 


\section{Figure Legends}

Figure 1. Box plots illustrating $1^{\text {st }} / 3^{\text {rd }}$ quartiles, medium and maximum levels of serum cartilage oligomeric matrix protein (COMP) in the IgE-negative control group, juvenile idiopathic arthritis (JIA), and hospitalized patients with ongoing infection respectively.

Figure 2. Diagram to illustrate circulating levels of cartilage oligomeric matrix protein in relation to C-reactive protein among referents with IgE-negative allergy tests (IgE referents), patients with juvenile idiopathic arthritis (JIA), and hospitalised patients with ongoing infection. 
Fig. 1
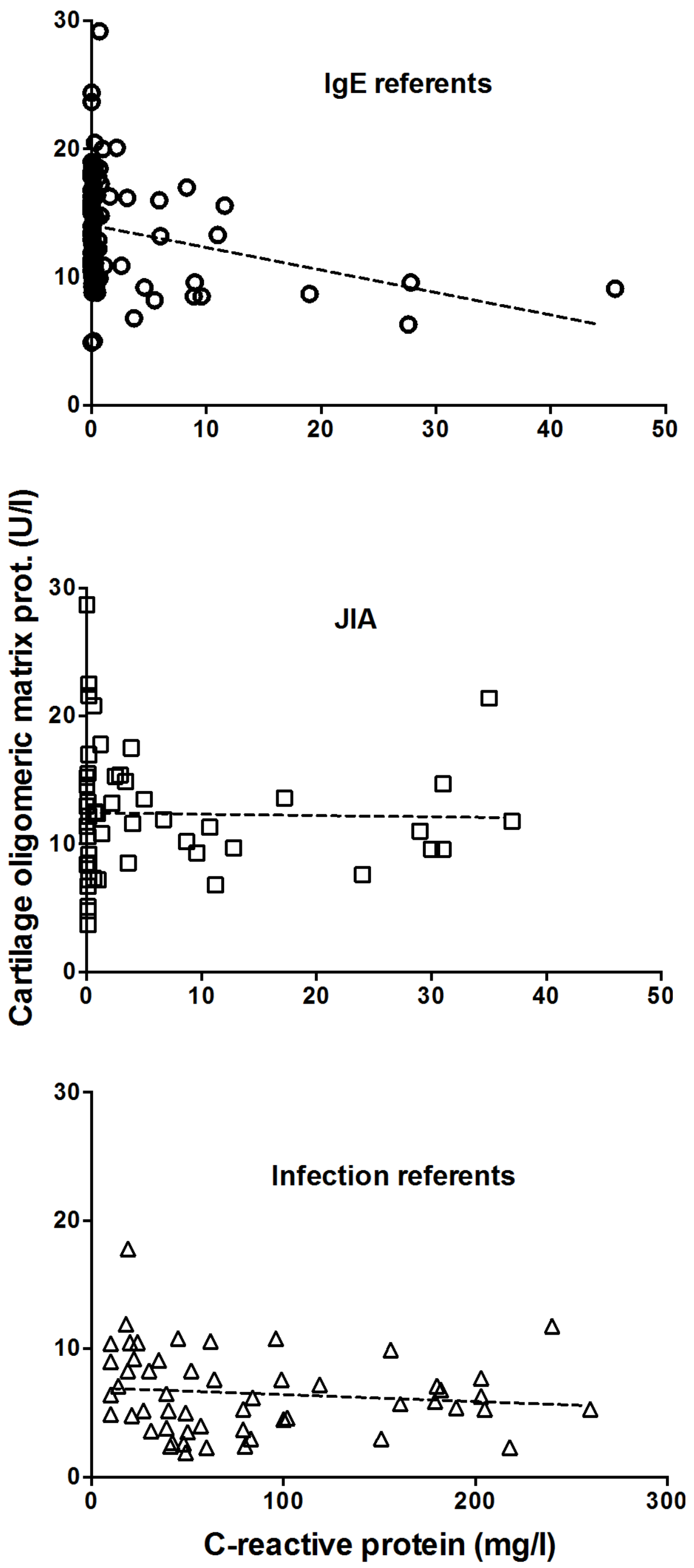
Fig 2.

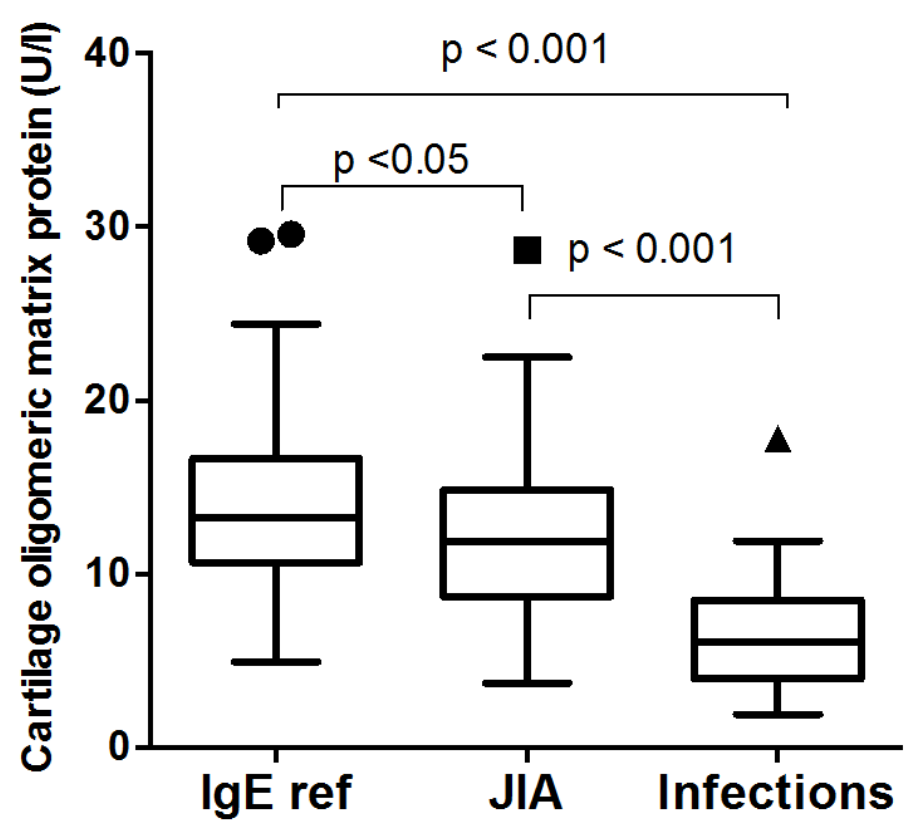

